\title{
II. ESTUDIOS
}

\section{INFORTUNIO Y VIRTUD: PETRARCA, VIVES Y EL INCA GARCILASO DE LA VEGA}

\author{
Sarissa Carneiro \\ Universidad de Chile \\ sarissacarneiro@gmail.com
}

RESUMEN/ABSTRACT

Este ensayo analiza la relación entre infortunio y virtud en La Florida del Inca (1605) del mestizo cuzqueño Garcilaso de la Vega, estableciendo un diálogo con la filosofía moral del Renacimiento, en especial con De remediis utriusque fortunce (1366) de Francesco Petrarca e Introductio ad sapientiam (1524) de Juan Luis Vives. Se destaca el relieve que adquieren, en la crónica primeriza del Inca, la valoración de la fortuna adversa, la preocupación por la "depravación" de los juicios, causada por el gobierno de las pasiones, y el aprovechamiento de la sabiduría de los indios como ejemplos de virtud para los cristianos. Se vincula, finalmente, la vertiente moral de la crónica del Inca con el ideal político y filosófico de la concordia entre el Viejo y el Nuevo Mundo.

Palabras Clave: historiografía de América colonial, filosofía moral del Renacimiento, humanismo.

This essay aims to analyze the relationship between misfortune and virtue in La Florida del Inca (1605) by the mestizo Inca Garcilaso de la Vega, considering its dialogue with the moral philosophy of the Renaissance, in particular with De remediis utriusque fortunce (1366) by Francesco Petrarca and Introductio ad sapientiam (1524) by Juan Luis Vives. The analysis emphasizes the importance of the value of misfortune, the consequences of the corruption of judgment, caused by the governance of passions, and the use of Indian wisdom as examples of virtue to Christian readers of the chronicle. Finally, the essay establishes a relationship between the moral positions of the text and its political and philosophical ideals of concord between the Old and New World.

KEY WORDS: Colonial Latin American Historiography, moral philosophy of the Renaissance, Humanism. 
El siete de abril de 1538, salió del puerto de San Lúcar Barrameda una de las más espléndidas armadas jamás vistas rumbo al Nuevo Mundo: la de Hernando de Soto al extenso territorio conocido entonces como la Florida. De aparato magnífico, se destacó por la gallardía y gentileza de sus caballeros y soldados, un total de novecientas cincuenta personas en siete navíos grandes y tan abastecidos de "todo matalotaje" que, según uno de sus cronistas, se le dio a cuantos iban en el viaje "ración doblada" (Garcilaso de la Vega, La Florida del Inca 24).

Los caballeros ilustres, hidalgos y soldados prácticos en el arte militar habían acudido a la publicación de títulos y cargos de la nueva empresa impresionados, quizás, por el hecho de que el adelantado Hernando de Soto invertía en ella los cien mil ducados ganados en la conquista del Perú, y así, dejando tierras, parientes y haciendas, se sumaban a la que creían sería una conquista tan rica como las recién pasadas de Perú y México.

De los casi mil cristianos que pasaron a la Florida, regresaron no más de trescientos: en embarcaciones improvisadas y luego de sufrir incomportables trabajos, llegaron "desfigurados, negros, flacos y secos, descalzos y desnudos" (La Florida del Inca 429). El adelantado Hernando de Soto, muerto en la Florida, había tenido un funeral lamentable: enterrado dos veces, descansó finalmente en las aguas del Río Grande. Quien había sido una de las mejores "lanzas" de la conquista (La Florida 349), caballero digno de grandes estados y señoríos (La Florida 348), fenecía así en la demanda, tras gastar en ella hacienda y vida.

El caso parecía ejemplificar para un hombre del siglo XVI la afición de la inconstante y cruel Fortuna en hacer descender súbitamente a quienes han subido a la más alta cumbre: dice el Hidalgo de Elvas, uno de los participantes de la expedición y autor de una crónica sobre la misma, "faleceo ho magnánimo, virtuoso e esforçado capitam Dom Fernando de Souto (...) que a fortuna sobio como soe fazer a outros, pera de mais alto cahir" (Relação verdadeira 176$)^{1}$.

1 "Falleció el magnánimo, virtuoso y esforzado capitán Don Hernando de Soto, a quien la Fortuna subió, como suele hacerle a muchos, para que de lo más alto cayera”. 
Pero la desventura de Hernando de Soto y de toda su armada hacía pensar no solo en el poder de la inestable fortuna sino en la relación entre infortunio y virtud. En la tradición iconográfica, Fortuna aparece frecuentemente opuesta a sabiduría y virtud: en "El camino de la virtud o historia de la Fortuna", realizado entre 1505 y 1508, a partir de un dibujo de Pinturicchio, la diosa desnuda aparece con un pie sobre la esfera y el otro sobre una nave, dando la espalda a los sabios que de ella se han apartado al elegir el camino de la virtud (González García 31, Figura 1).

En ese sentido, el caso de Soto aportaba un material narrativo apto también para una consideración de tipo moral. En La Florida del Inca (1605), el mestizo cuzqueño Inca Garcilaso de la Vega indaga en torno a las razones del fracaso de Soto y atribuye la desdicha de la armada a la discordia entre españoles, ocasionada por un motín que había suscitado en De Soto, "hombre tan celoso de su honra", "precipitados y desesperados afectos" ( $L a$ Florida 272). Según Garcilaso de la Vega, el parecer "apasionado" y falto de "juicio libre" del adelantado, y no la Fortuna, lo habría llevado a la propia destrucción (272).

En la crónica del Inca se introducía, así, un asunto objeto de diversas consideraciones en los autores del Renacimiento. Ernst Cassirer se refirió a la doctrina filosófica renacentista en torno a la relación libertad y necesidad y si bien observó que la filosofía del Renacimiento aportó poco a los motivos puramente dialécticos de este problema eterno e invariable, identificó un nuevo dinamismo en la esfera intelectual, un esfuerzo hacia lo que llamó, con Warburg, un nuevo estado de equilibrio energético (Cassirer 123, Warburg $232)^{2}$. Aby Warburg, al trazar las transformaciones del símbolo Fortuna en las artes plásticas del primer Renacimiento, llamó la atención a la presencia de la diosa como signo e imagen que ilustraba simbólicamente la vida íntima del individuo (232). Como símbolo antiguo de la energía que envuelve las cosas y decide la suerte, la Fortuna aparece en oposición al individuo singular, en su lucha con el mundo (232) ${ }^{3}$. En el período de transición estudiado por Warburg, Fortuna aparece como formulación figurativa del conflicto entre

2 "Nell'uso metaforico di figure antiche, tanto Sassetti che Rucellai rivelano infati come, in quell'epoca di transizione dell'atteggiamento soggettivo, essi aspirino ad uno stato di equilibrio nuovo fra energie diverse" (Warburg, 232).

3 Señala Warburg al describir el emblema de Rucellai "Avventurarsi nella lotta per l'esistenza significava per Rucellai occupare sulla nave il posto del timoniere; cosí egli superava, con sua stessa umile meraviglia, i tempi delle aversità, navigando molto a punto 
la fuerza de la personalidad individual y la potencia enigmática de la suerte (232), conflicto que adquiere un sentido de compromiso, equilibrio y aun honesta conciliación (246). Según Cassirer, esta fórmula conciliadora se advierte también en la filosofía, donde se persigue una conciliación teórica entre la fe en Dios y la fe en sí mismo, propia del hombre del Renacimiento (123).

Uno de los aspectos involucrados en este asunto se refiere a la relación entre fortuna y virtud. Si bien hay que atender a los matices particulares atribuidos a la virtud en las diversas formulaciones ${ }^{4}$, distintos autores subrayan el poder de la virtud frente a los embates de la fortuna. Para Poggio Bracciolini, por ejemplo, los asaltos de la fortuna tienen distinto relieve dependiendo de las etapas de la vida humana, pero son la virtus y el studium los que pueden vencer las enigmáticas fuerzas del cielo (Cassirer 124). Marsilio Ficino, en la célebre carta que responde a la pregunta de Giovanni Rucellai en torno al alcance de la razón humana y de la sagacidad práctica contra los casos de fortuna, recomienda la paz o tregua con la voluntad de esta última, pero aconseja, en el caso del combate, las armas de la "prudencia, paciencia y magnanimidad" (Warburg 235). En este armisticio con la Fortuna, la propuesta de Pico della Mirandola amplía el protagonismo del individuo al centrar el tema en la dignidad del hombre como artífice libre e independiente de sí mismo (Cassirer 139). También Pico insiste en que la fuerza de la fortuna se contrapone con la fuerza de la virtus y que el destino se contrapone con la voluntad consciente de sí y confiada en sí misma (Cassirer 191). Giordano Bruno, en 1584, privará a la inestable e inconstante Fortuna de cualquier puesto en el universo, dando a Fortaleza en cambio el papel de tutela de las virtudes, custodia de la justicia, inexpugnable a los vicios, constante en los peligros, rígida contra las voluntades y domesticadora de la Fortuna (Cassirer 129).

El texto iniciador del tratamiento renacentista de la relación fortuna y virtud es De remediis utriusque fortunce de Francesco Petrarca. Con claridad

e senza errore" (238). Para otras representaciones figurativas de la Fortuna en relación con Virtus y Occasio, véase también Wittkowe, "Chance, time and virtue".

4 Al respecto advierte Kristeller, "The lines between decency and success are not always clearly drawn as we might wish, and as a result, the word virtue came to have a curious ambiguity. It meant moral virtue, to be sure, but Machiavelli's virtù stood more for the strong character that assured political success, and the 'virtuoso' was distinguished by intellectual and social skill rather than by moral excellence" (30). 
insiste allí Razón, en diálogo con las cuatro pasiones Esperanza, Gozo, Dolor y Temor, que solo la virtud nos puede hacer vencedores en la guerra con la Fortuna. Es la virtud y no la fortuna la que nos hace libres $(\mathrm{x})^{5}$, pues sobre la virtud se funda el verdadero y firme poder (LX), la verdadera virtud menosprecia las amenazas de la fortuna $(\mathrm{CVv})$.

La virtud, a diferencia de la fortuna,

Ninguna cosa niega sino que aquello que dado podría dañar y quitado aprovechar. Y ninguna cosa quita sino aquello que tener es dañoso y perdiendo provechoso. No delata, no es mandona, no se arrepiente, no arruga la frente, no pone ceño, ninguno menosprecia, a ninguno desampara, a ninguno engaña, no es cruel, no sañosa, no mudable, en todo tiempo y lugar es una (LXXXIX).

A partir de esto concluye Petrarca en el diálogo "De dudoso estado" que la fortuna se puede doblar e incluso quebrantar, "todo aguijón de la fortuna con la virtud se quebranta. Y el que de esta estuviere armado no ha menester manos para ser fuerte" (CXXVII).

En 1524, el humanista valenciano Juan Luis Vives precisa en su Introductio ad sapientiam la vinculación infortunio y virtud desde una perspectiva cristiana: "Todos los males que llaman del cuerpo, como enfermedades, y los de la fortuna, como son pérdidas y desgracias, tendremos por muy buenos si los sufriéremos con paciencia, y tanto seremos más hábiles para obrar virtud cuanto menos bien nos sucedieren las cosas, que muchas veces con estos males se aumentan y hacen mayores las virtudes" $(15)^{6}$. La virtud sigue en el centro de un texto como el de Vives que también defiende la libertad y la dignidad del individuo: "la reina y princesa la más preciosa de todas las cosas es la virtud, a la cual todas las otras cosas, usando de su oficio, y haciendo lo que deben son obligadas a servir" $(4)^{7}$.

5 El número de folio corresponde a la edición de Zaragoza, 1518, en la traducción de Francisco de Madrid, De los remedios contra próspera y adversa fortuna. Se actualiza la ortografía.

6 Se cita por la traducción de Francisco Cervantes de Salazar en la edición de Madrid, 1772. Esta traducción circuló en España desde 1544.

7 Nótese no obstante el concepto de virtud de Vives: "Virtutem voco pietatem in Deum, et hominis, cultam Dei, et amores in homines, voluntatemque benefaciendi. Reliqua, si quis ad virtutem hanc referat, non mala videbuntur." (Opera Omnia, Tomus I, 3). 
Si el asunto recibió diversos tratamientos en tratados, diálogos, cartas y otros tipos textuales que dan cuenta del relieve de la filosofía moral entre autores del Renacimiento y, especialmente, entre humanistas, ocupó también un espacio en la escritura histórica a partir de la antigua noción de la historia como magistra vitae, lo que impulsó asimismo un contenido biográfico cada vez más extenso que venía a ofrecer, en consonancia con la dimensión moral de la historiografía renacentista, modelos de comportamiento humano a los lectores ${ }^{8}$.

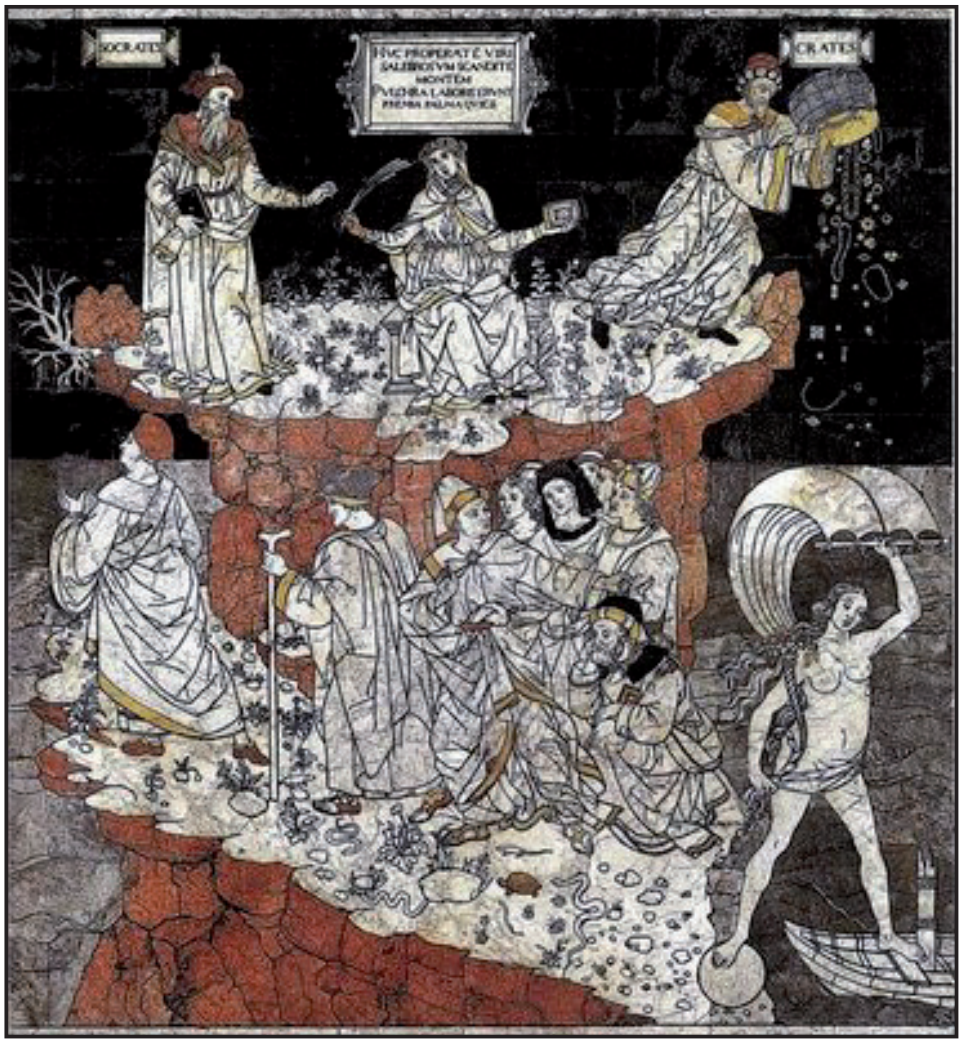

Figura 1. "El camino de la virtud o historia de la Fortuna", Catedral de Siena

8 Como sintetiza Kristeller, "another branch of study cultivated by humanists, history, had moral significance for them. The humanists shared the view of many ancient and medieval authors that one of the tasks of historiography is to teach a moral lesson. Much Renaissance historiography is sustained by this belief. In the same way, the extensive biographical literature produced during the period is often animated by the desire to supply the reader with models worthy of imitation" (27). 
En la biblioteca del Inca Garcilaso de la Vega, estudiada por José Durand en base al inventario de sus bienes, se encontraban numerosas obras que trataban directa o indirectamente el problema apuntado: Theatro de varios acaecimientos de la fortuna de Girolamo Garimbeto, Teatro del mundo en el cual ampliamente se trata de las miserias del hombre de Pierre Boaistau, Della instituzione morale y Della instituzione di tutta la vita de l'uomo nato nobile e in città libbera, ambos de Alessandro Piccolomini, Discursos morales de Juan de Mora, los Diálogos de amor de León Hebreo, traducidos por el mismo Inca, y los que nos interesan particularmente aquí, Remedios contra próspera y adversa fortuna de Petrarca e Introducción a la sabiduría de Juan Luis Vives 9 .

Como es sabido, en la discusión de asuntos morales, los autores del Renacimiento hicieron un uso ecléctico de la tradición: como subrayó Kristeller, la influencia de la ética antigua en el Renacimiento no se limitó a una aceptación de teorías sistemáticas sino que se verificó en un uso variado de ideas antiguas, ejemplos y sentencias, uso característico de los humanistas y sus seguidores (Kristeller 37). Distintas perspectivas fueron armonizadas y extraídas de diversos escritos en la búsqueda de una sabiduría común que pudiera ser enseñada, imitada y utilizada (Kristeller 37). Estos extractos eran reunidos por cada uno para su posible utilización posterior en cuadernos como los que describe Juan Luis Vives: "Tendrás un libro en blanco en el cual notarás lo que leyeres, u oyeres, que sea agudo, sabio, o no común, necesario para el cotidiano hablar, porque cuando sea necesario usar de ello, lo tengas a mano" (Introducción a la sabiduría 34).

El material que el Inca Garcilaso de la Vega "tuvo a mano" para la escritura de La Florida del Inca fue amplio, como bien registraron los ya clásicos estudios de Aurelio Miró Quesada o de José Durand, e incluyó probablemente no solo las obras mencionadas más arriba sino clásicos de la Antigüedad y

9 El estudio de Durand se apoya en el inventario hecho por los albaceas del Inca Garcilaso de la Vega. Como aclara el mismo Durand, el amanuense copia “de oído" los títulos en algunos casos suprimiendo el nombre del autor, el apellido o incluso el título de la obra ("La biblioteca del Inca" 242). Las entradas a las que nos referimos son: "94 Yntroduzión a la sabiduría" que Durand identifica como de Luis Vives (253), y "120 Dos cuerpos del Pletarca" así como "127 El Pretarca" (255). A pesar de que la referencia a la obra de Petrarca es general, no se duda en afirmar el conocimiento del Inca de los Remedios (véase Durand, El Inca Garcilaso, clásico de América 70). 
del Renacimiento, obras de filosofía política, de preceptiva historiográfica y retórica, obras religiosas y científicas, así como obras literarias ${ }^{10}$.

Como acercamiento preliminar al problema del alcance de la formación intelectual del Inca Garcilaso de la Vega en el tratamiento cronístico de la relación fortuna y virtud en una obra como La Florida del Inca (1605), interesa puntualizar aquí una línea de pensamiento que enfatiza la necesidad de erradicar las pasiones humanas y atender a la virtud como bien supremo particularmente en las obras citadas de Petrarca y Juan Luis Vives.

Entre las obras latinas de Petrarca, De remediis utriusque fortunce (terminada de escribir en 1366) fue durante mucho tiempo la más influyente y popular. Impresa en 1468, tuvo setenta ediciones hasta el siglo XVIII. En España y Portugal fue la obra dominante en cuanto fuente de la filosofía moral de Petrarca, como observó Deyermond. Fue traducida al castellano a comienzos del siglo XVI por Francisco de Madrid, traducción impresa en Valladolid en 1510 con seis reimpresiones hasta 1534 (Deyermond III) ${ }^{11}$.

El De remediis constituyó, según afirma George McClure, el más ambicioso y sistemático esfuerzo de Petrarca como medicus animorum: allí, el Petrarca consolador de sus propios infortunios o de los de amigos y parientes, asume la voz estoica triunfante del que se opone a la Fortuna universalizando una sabiduría hacia un extenso universo de lectores y situaciones (McClure 46-53). En el Libro I, 122 capítulos detallan las tentaciones, vanidades y distracciones de la fortuna próspera, mientras en el Libro II, 132 capítulos ofrecen consuelo frente a las miserias de la fortuna adversa. En ambos libros, Petrarca conjuga las raíces estoicas con temas cristianos como la vanitas o el contemptus mundi, pero como observó George McClure, el marco es fundamentalmente secular:

10 Como advierte Durand, el inventario de la biblioteca del Inca Garcilaso nos permite un conocimiento solo parcial de sus lecturas. Su misma obra da cuenta de la importancia de textos y obras que no se encuentran en dicho inventario. Durand lo atribuyó al traslado de Montilla a Córdoba en 1591, cuando el Inca "es probable (...) que se deshiciese de algunos volúmenes de su biblioteca", la inventariada "es la biblioteca de un hombre de edad avanzada, de un anciano solitario y desengañado que muere dejando terminada su obra, ya sin lazo alguno capaz de retenerlo en este mundo" ("La biblioteca" 264).

11 Para la recepción de Petrarca en los autores del Renacimiento, consúltese también Petrarch and his readers in the Renaissance, editado por Karl Enekel y Jan Papy. 
A lay "Ratio" replacing the pastoral "Agustinus" of the Secretum, the scheme of the four Stoic affects fully dominating that of the deadly sins (...) De remediis basically aims to treat the cura animorum filling in the psychological gaps left by the pastoral cura animarum (McClure 207-208).

Se trata, según McClure, de una consolación antropocéntrica de la dignidad del hombre, lo que constituiría el giro particular de esta obra máximamente influyente.

Del complejo edificio de De remediis nos interesa particularizar aquí, por el relieve que tiene en La Florida del Inca, la consideración de la buena fortuna como más difícil y temerosa que la adversa (De remediis II). La fortuna próspera fácilmente conduce a la soberbia, en ella se requiere freno para reprimir el ánimo, pues frente a la prosperidad nuestra humanidad -ya regalada- olvida su propia condición. "Muchos he visto", dice Petrarca en la traducción de Francisco de Madrid, "que con buen corazón sufrieron daños, pobreza, destierro, cárcel, tormentos y enfermedades peores que la muerte: mas ninguno que las riquezas, las honras ni la potencia" (II). El peligro aparejado a la prosperidad no se limita a la soberbia sino que radica también en la súbita caída. En el diálogo "De Fortuna favorable", Razón advierte: "De lo alto son las grandes caídas y en el alto mar pocas veces se halla reposo, de lo bajo no temas la caída ni en seco ahogarte" (XIIIv). En la voluble rueda de la fortuna el que está más alto está más cerca de caer, lo que se advierte también para la abundancia de riquezas: estas son una dudosa y pesada prosperidad que trae más envidia que placer; la riqueza, difícil de ganar, congojosa de guardar y triste de perder, acrecienta la codicia y disminuye la fe en la virtud. La gran prosperidad, en síntesis, abre el camino para la adversidad, "espinosa es la subida de esta escalera humana y mil resbaladeros tiene. Temeroso y tremiloso el estar en la cumbre y muy espantoso el caer" (LIX).

Con similares consideraciones, el Inca Garcilaso de la Vega hace referencia a su propia fortuna adversa en el "Proemio al lector" de La Florida del Inca. El mestizo destaca su desengaño en relación con los favores de la fortuna y las mercedes temporales a las que podría aspirar como retribución por la participación de su padre en la conquista del Perú o por su propia obra ${ }^{12}$ :

12 En concreto, por su traducción de los Diálogos de amor de León Hebreo, Traducción del indio, cuya primera dedicatoria (1586) está dirigida a Felipe II. 
Ni pretendo ni espero por este largo afán mercedes temporales, que muchos días ha desconfié de las pretensiones y despedí las esperanzas por la contradición de mi fortuna. Aunque, mirándolo desapasionadamente, debo agradecerle muy mucho el haberme tratado mal, porque, si de sus bienes y favores hubiera partido largamente conmigo, quizá yo hubiera echado por otros caminos y senderos que me hubieran llevado a peores despeñaderos o me hubieran anegado en ese mar de sus olas y tempestades, como casi siempre suele anegar a los que más ha favorecido y levantado en grandezas de este mundo; y con sus disfavores y persecuciones me ha forzado a que, habiéndolas yo experimentado, le huyese y me escondiese en el puerto y abrigo de los desengañados, que son los rincones de la soledad y la pobreza, donde, consolado y satisfecho con la escasez de mi poca hacienda, paso una vida, gracias al Rey de los Reyes y Señor de los Señores, quieta y pacífica, más envidiada de ricos, que envidiosa de ellos (9).

El argumento consolatorio que insiste en la idea de la prosperidad como puerta de la adversidad, al tiempo que encarece la virtud aparejada a la escasez de hacienda, instala la escritura de la crónica en el marco de la "recreación del ánimo", cosa necesaria, según Petrarca, para enfrentar la fortuna adversa ${ }^{13}$. La obra que redunda de tal "recreación" persigue, no obstante, un reconocimiento que desatiende las recomendaciones del cura animorum: si en De remediis Petrarca califica de cosa "vana" escribir libros para ganar honra, es justamente este "mejor nombre" el que busca el mestizo al escribir La Florida: "espero en Dios que estos trabajos me serán de más honra y de mejor nombre que el vínculo que de los bienes de esta señora [Fortuna] pudiera dejar. Por todo lo cual, antes le soy deudor que acreedor" pues "me deja ofrecer y presentar esta historia a todo el mundo" (La Florida del Inca 9).

Ahora bien, el pasaje autobiográfico tiene la importancia de instalar el historiador en una vertiente moral que será tanto la que pretende orientar la conducción de su propia vida, como la que utiliza para juzgar las acciones narradas en su crónica. Dicho en otros términos, desde el "puerto y abrigo

13 "Ambas caras de la fortuna se deben temer, una ha menester freno y la otra recreación. En la una se ha de reprimir la soberbia y el ánimo y en la otra recrear y sobrellevar la fatiga" (De remediis $\mathrm{II}$ ). "Por no estar ocioso, que cansa más que el trabajar, he dado en otras pretensiones y esperanzas de mayor contento y recreación del ánimo que las de la hacienda..." (La Florida del Inca 9). 
de los desengañados", como ideal moral, el cronista narra y comenta los infortunios de la expedición de Hernando de Soto a la Florida.

Este juicio del cronista parece querer responder, como advertí en otro momento $^{14}$, a la apreciación del vulgo que frente a casos como el de Soto afirmara, con "malicia" y "sobra de envidia", que "a costa de locos, necios y porfiados, sin haber puesto caudal mayor, ha comprado España el señorío de todo el nuevo mundo" (La Florida 13). Frente a lo cual el Inca-él mismo hijo de un conquistador del Perú- defiende como el "mayor caudal" que tuvo España justamente el criar y producir hombres que ganaran un mundo nuevo haciéndose temer del viejo (La Florida 13). A lo largo de la crónica, y en consonancia con ideales morales de raíz estoica, el Inca encarece sobre todo las penurias, trabajos, adversidades y tormentos sufridos por los primeros conquistadores. Casos particulares como los ocurridos en la expedición de Hernando de Soto a la Florida, deberían dar cuenta del resto como el "dedo del gigante" hace imaginar el "grandor del cuerpo", dice el historiador ${ }^{15}$.

Pero el Inca va más allá de esta defensa: su narración, al mismo tiempo que rescata los méritos de sujetos como Hernando de Soto, localiza y precisa los errores de expediciones como la de la Florida. El cronista centra el problema en el individuo y muy particularmente en sus dificultades para gobernar las propias pasiones. Como en De remediis, también en La Florida del Inca tienen particular relieve las pasiones de la ira y la codicia ${ }^{16}$. La codicia del interés, afirma el mestizo ya en un capítulo inicial de la crónica, ciega el juicio a los hombres aunque sean ricos y nobles (44). Es la codicia la que lleva a los expedicionarios a amotinarse y a abandonar finalmente las tierras exploradas. La discordia y el motín provocan la ira en Soto, una ira que ciega

14 "La Florida del Inca (1605) de Garcilaso de la Vega: ética y buen gobierno a propósito del cautiverio de Juan Ortiz".

15 "Por esto poco que hemos contado que pasaron en esta breve jornada, se podrá considerar y ver lo que los demás españoles habrán pasado en conquistar y ganar un nuevo mundo, tan grande y tan áspero como lo es de suyo" (La Florida del Inca 159).

16 "La codicia humana arde más cuanto más se le acrecienta, y creciendo el oro crece la sed de ello mismo y el deseo de buscarlos y disminuye la fe en la virtud, en lo cual consiste la muerte del alma" (De remediis XLII). "Ninguna cosa hay menos convenible al hombre [que la ira] antes es propia de fieras: y aun no de todas mas de las muy crueles y feroces. Ninguna cosa hay que menos convenga al hombre que la crueldad y fiereza y al contrario no hay cosa más propia suya que la misericordia y mansedumbre, cuyo contrario principal es la venganza y todo aquello que con acelerado ánimo un hombre comete ásperamente contra otro" (De remediis LXVIv). 
su juicio y causa su propia destrucción (La Florida 272). La discreción de Soto no resiste la instigación del desdén (272) y, "apasionado", ya no puede regirse y gobernarse con la claridad y el juicio libre que "las cosas graves requieren" (272).

La gravedad de la pérdida del juicio libre que padece Soto en la pluma del Inca recuerda el énfasis que se concede a ello en otro texto máximamente divulgado en la época, Introductio ad sapientiam (1524) de Juan Luis Vives ${ }^{17}$ : "no hay en la vida humana cosa más dañosa que la depravación de los juicios cuando a cada cosa no se le da su precio" (1). Como afirmó Gómez-Hortigüela, la sabiduría de Vives es al mismo tiempo una virtud intelectual, de perfección de la inteligencia que capta y contempla la verdad, y una virtud moral, perfección del comportamiento en consonancia con un ideal de vida lograda (99). Con igual énfasis que Petrarca, pero desde el humanismo cristiano, el valenciano rechaza las pasiones de la codicia y la ira. La codicia es fuente de gran trabajo, impide al ser humano ser libre pues es libre solamente el que desea lo que está en su mano. La ira, por su parte, es la más furiosa pasión, peor que ninguna, pues hace del hombre una bestia fiera (43). La ira ciega especialmente el juicio:

Cualquier perturbación del alma oscurece la claridad del entendimiento y embota el juicio, de manera que no pueda conocer bien las cosas: pero la ira ciega tanto más al hombre que le hace que ni pueda ver lo que le conviene ni lo que le hace daño, sino que como bestia nada haga con razón.

(...) Por este mal vicio que al hombre hace andar furioso, cruel y mal encarado, pierde el varón toda su autoridad, vánsele los amigos, espántanse los que le encuentran; doquiera está solo, ninguno le habla, y todos le aborrecen.

Por lo cual todos los varones sabios en ninguna cosa procuraron serlo más que en huir de la ira y resistirla tanto que pelearon con su natural condición y la vencieron (Introductio 44-45).

17 Introductio ad sapientiam fue un libro muy divulgado sobre todo en la formación de jóvenes. Después de la edición de Lovaina (1524) se reimprimió numerosas veces (Brujas, 1526; París, 1527; Amberes, 1530; treinta ediciones en latín hasta el siglo XVIII, quince en español desde la edición de Burgos, 1544, hasta 1886. Ver detalles en Gómez-Hortigüela 207. 
Sin embargo, aún más significativo es, en relación con el tema que aquí se aborda, el uso de esa sabiduría de los antiguos en Juan Luis Vives. La lectura de los antiguos, ejemplos de virtud y bondad, sirve, según el humanista, de contraste al cristiano que, por la luz de la fe está aun más obligado a la virtud que el hombre de la Antigüedad:

También leemos para usar de los testimonios y dichos de los varones sabios, contra los que otros dijeron contrario a esta verdad: la cual estos no pudieron ver ni sufrir (...) Leemos, asimismo, para que, viendo la gran virtud y bondad que en estos gentiles había, entendamos con cuánta mayor razón debe haber en un cristiano, discípulo de Dios, maestro nuestro: y así por la luz de la fe que el cristiano tiene, es sin comparación alguna más obligado a vivir bien (Introductio 26).

Similar argumento aparece en La Florida del Inca, pero con la significativa diferencia de que no son los antiguos sino los indios virtuosos como el cacique Mucozo los que obligan a los cristianos a la virtud:

Basta representar la magnanimidad de un infiel para que los príncipes fieles se esfuercen a le imitar y sobrepujar, si pudieren, no en la infidelidad, como lo hacen algunos indignos de tal nombre, sino en la virtud y grandezas semejantes a que por la mayor alteza de estado que tienen están más obligados. Que cierto, consideradas bien las circunstancias del hecho valeroso de este indio y mirado por quien y contra quien se hizo, y lo mucho que quiso posponer y perder, yendo aun contra su propio amor $\mathrm{y}$ deseo por negar el socorro y favor demandado y por él prometido, se verá que nació de ánimo generosísimo y heroico, indigno de haber nacido y de vivir en la bárbara gentilidad de aquella tierra. Mas Dios y la naturaleza humana muchas veces en desiertos tan incultos y estériles producen semejantes ánimos para mayor confusión y vergüenza de los que nacen y se crían en tierras fértiles y abundantes de toda buena doctrina, ciencias y religión cristiana. (La Florida 55).

Así, la crónica apunta a otro de los temas más trascendentes de la filosofía moral del Humanismo, el que se refiere a las virtudes del príncipe cristiano, objeto de espejos de príncipes y tratados de buen gobierno ${ }^{18}$. En fragmentos

18 Entre humanistas, la educación de hijos de nobles fue una actividad frecuente, lo que dio un marco específico a la tradición de las propuestas de buen gobierno (Véase Kristeller 47-48). 
dispersos de la crónica, se va construyendo una imagen ideal de gobernante cristiano centrada particularmente en la virtud de la magnanimidad, la generosidad, la clemencia, la atención a la fe jurada, el dominio sobre las pasiones (en especial, sobre la ira y el enojo que impulsa la venganza), y, no menos importante, la capacidad para escuchar consejos. La desatención a los consejos que, recordemos, es criticada por el Inca en relación con Hernando de Soto, aparece como un problema general de "libres y poderosos" (73). A propósito de Vasco Porcallo, el Inca reflexiona

En casos graves, siempre las determinaciones no consultadas con la prudencia y consejo de los amigos suelen causar arrebatados y aun desesperados arrepentimientos (...) Mas, ¿quién domará una bestia fiera ni aconsejará a los libres y poderosos, confiados de sí mesmos y persuadidos que conforme a los bienes de fortuna tienen los del ánimo y que la misma ventaja que hacen a los demás hombres en la hacienda que ellos no ganaron, esa mesma les hacen en la discreción y sabiduría que no aprendieron? (La Florida 73).

La no correspondencia entre fortuna/hacienda y discreción/sabiduría guarda relación con el concepto de nobleza que acoge el Inca en su crónica. "No puede haber nobleza donde no hay virtud" (265), sostiene el mestizo en la línea de lo que el humanismo venía defendiendo con claridad en tratados sobre la nobleza como el De nobilitate ${ }^{19}$. Esta afirmación abarca en la narración histórica del Inca, tanto a europeos como a indios y es justamente en un indio, el caballero mozo de la señora de Cofachiqui, que Garcilaso advierte la correspondencia entre "nobleza de sangre" y "generosidad de ánimo", tenidos por el cronista como un conjunto comparable a "la fruta y el árbol" (La Florida 213).

Como advirtió Hopkins Rodríguez, el Inca considera el arquetipo caballeresco o cortesano un "modelo universal de conducta humana elevada"

19 Kristeller destaca los tratados de Poggio Bracciolini, Buonaccorso da Montemagno y Bartolomeo Platina, todos defensores de la idea de que la nobleza descansa en la virtud "the thesis that nobility rests on virtue is strongly defended" (48). La afirmación, que tiene antecedentes en Boecio, tiene lugar también en De remediis y en Introductio ad sapientiam. Petrarca en De remediis encarece al de vil linaje "Si acuerdas de seguir el camino de la virtud por donde muy pocos van tanto serás más claro cuanto de mayor tinieblas suprimido" (LXXXV). Vives afirma, por su parte (como hará luego el Inca), "La verdadera y entera nobleza de la virtud nace" (Introductio 9). 
(241), lo que se conecta con el énfasis puesto en La Florida del Inca en la universalidad de la naturaleza humana, sustentado en el concepto de ley natural $(236)^{20}$. Al proponer la conducta noble de los indios como un "texto social homólogo al de los europeos”, el Inca va más allá de la preocupación moral e instala un proyecto político que aboga por una relación entre Europa y América "más acorde con principios de equidad" (Hopkins Rodríguez 231).

De este modo, la dimensión moral de La Florida del Inca se conecta con inquietudes permanentes en la producción del mestizo cuzqueño, particularmente con la lucha contra la "frustración cultural", como lo llamó Hopkins Rodríguez, y con el afán "uniformista y armonizador" que, como observó Raquel Chang-Rodríguez, aspira a la integración y a la concordia en las relaciones hispano-indias, al mismo tiempo que advierte las dificultades para la concreción de ese ideal de la filosofía de los Diálogos de amor (36).

El cumplimiento de estas aspiraciones del plano político está en estrecha conexión con el ideal moral que el Inca presenta en su crónica, en consonancia, como vimos, con la filosofía moral del Renacimiento y el Humanismo. La discordia es también, como dijera Petrarca en el prólogo del Libro II de De remediis, la discordia interna del individuo que, en las secretas entrañas del ánima hacen del camino de esta vida un tempestuoso y turbio mar (LXXXIv). Desde este punto de vista, concordia y discordia adquieren otros matices: "los vicios son los que entre sí discordan, que entre las virtudes siempre hay gran concordia" (CXXVI).

Así, el infortunio de la expedición de Hernando de Soto permite al Inca Garcilaso de la Vega dar cumplimiento al llamado de la historia a la ejemplaridad que aporta "experiencia, prudencia y formación de costumbres" como preceptúa Vives en De ratione dicendi ${ }^{21}$. La "experiencia" que deriva de la narración de la expedición a la Florida, en lo que se refiere a la relación

20 Sobre este asunto, pueden consultarse también Avalle-Arce (20-28) y ChangRodríguez, "Sobre la vertiente filosófica de La Florida del Inca" (28). Otros estudios recientes aportan nuevas perspectivas en Nuevas lecturas de La Florida del Inca, editado por Carmen de Mora y Antonio Garrido Aranda, así como Franqueando fronteras: Garcilaso de la Vega $y$ La Florida del Inca, editado por Raquel Chang-Rodríguez.

21 Sobre la narratio de la historia: "Pero conviene que todos los escritos tengan una utilidad, para no arrepentirse de la pérdida de tiempo, cosa preciosísima, y cuanto más la historia, de la cual puede sacarse tanto provecho, a saber: experiencia de las cosas, prudencia, 
fortuna y virtud como aspecto del problema más amplio de la libertad y la necesidad, apunta a al menos tres sentidos distintos. Por un lado, la identificación de las pasiones no gobernadas por de Soto, raíz de su perdición, dispone hacia esa dignidad del hombre tan valorada por los hombres del Renacimiento: de haber actuado con mayor dominio sobre los afectos, Hernando de Soto podría haber doblegado la fortuna adversa haciendo de la Florida un nuevo México. Sin embargo, la desventura ofrece al historiador (refugiado él mismo en el "puerto y abrigo de los desengañados") un material que apunta al infortunio como ocasión para el aumento de virtudes, y eso tanto a un genérico lector, como también a los "libres y poderosos" que inciden en los destinos de América. Ese infortunio que hace mayor la virtud recibe finalmente un nuevo giro hacia una comprensión cristiana de la desventura vivida en la Florida: el capítulo final de la crónica hace un recuento de los cristianos seglares y religiosos muertos en tierras floridanas desde su descubrimiento para concluir que "es de creer y esperar que tierra que tantas veces ha sido regada con tanta sangre de cristianos haya de fructificar conforme al riego de la sangre católica que en ella se ha derramado" (448).

La presencia en la crónica de estos tres sentidos debe entenderse no solo como convivencia de distintas líneas de reflexión moral en un hombre con la formación intelectual del Inca Garcilaso de la Vega sino también en relación con el complejo proceso de redacción de La Florida del Inca, una obra, para usar las palabras de Aurelio Miró Quesada, "briosa, gallarda y sugestiva" en su concepción de juventud, "madura" en su redacción y "de vejez" en su publicación (153). Como observó José Durand, "el Inca Garcilaso que escribió La Florida no era el mismo que, años después, la enmendaba y corregía" ("La redacción" 302); ese largo proceso de escritura permitió la convivencia textual de un carácter épico, de un tono bravo en las acciones y descripciones y, al mismo tiempo, un carácter reflexivo de madurez e incluso desengaño (Durand, "La redacción"). Del mismo modo, el brío de la virtus con que Hernando de Soto podría haber conducido la expedición, se hace puerto y abrigo de desengañados y, finalmente, esperanza en la misericordia de Cristo frente a la sangre derramada. 


\section{BIBLIOGRAFÍA}

Avalle-Arce, Juan Bautista. "Introducción”. El Inca Garcilaso en sus Comentarios (antología vivida). Madrid: Gredos, 1970. 20-28.

Cassirer, Ernst. "Libertá e necessità nella filosofía della Rinascenza". Individuo e cosmo nella filosofia del Rinascimento. Trad. Federico Federici. Milano: Libri, 2001.

Chang-Rodríguez, Raquel. "Sobre la vertiente filosófica de La Florida del Inca". Violencia y subversión en la prosa colonial hispanoamericana, siglos XVI y XVII. Madrid/Maryland: Turanzas ediciones-Studia Humanitatis, 1982. 21-40.

De Mora, Carmen y Antonio Garrido Aranda, Eds. Nuevas lecturas de La Florida del Inca. Madrid/Frankfurt: Iberoamericana-Vervuert, 2008.

Deyermond, A. D. The Petrarchan sources of La Celestina. [1961]Westport, Connecticut: Greenwood Press Publishers, 1975.

Durand, José. "La biblioteca del Inca". Nueva Revista de Filología Hispánica 1/II (1948): 239-264.

"La redacción de La Florida del Inca: Cronología". Revista Histórica 21 (1954): 287-302.

El Inca Garcilaso, clásico de América. México: SepSetentas, 1976.

Enenkel, Karl y Jan Papy. Petrarch and his readers in the Renaissance. Leiden/Boston: Brill, 2006.

Garcilaso de la Vega, Inca. La Florida del Inca. Ed. Emma Susana Speratti. México: Fondo de Cultura Económica, 1956.

La traducción del indio de los tres diálogos de amor de León Hebreo. En Obras completas del Inca Garcilaso de la Vega. Tomo I. Ed. C. Sáenz de Santa María. Madrid: Biblioteca de Autores Españoles, 1960. 1-227.

Gómez-Hortigüela, Ángel e Ismael Roca, edición y estudio. Introducción a la sabiduría de Juan Luis Vives. Valencia: Ajuntament de València, Acción Cultural, 2001.

González García, José M. La diosa Fortuna. Metamorfosis de una metáfora política. Madrid: Mínimo Tránsito, 2006.

Hidalgo de Elvas. Relação verdadeira dos trabalhos que o governador D. Fernando de Souto e certos fidalgos portugueses passaram no descobrimento da Província Florida. [Évora, 1557] Ed. Maria da Graça Mateus Ventura. Lisboa: Comissão Nacional para as Comemorações dos Descobrimentos Portugueses, 1998.

Hopkins Rodríguez, Eduardo. "Lo ejemplar, lo sapiencial y lo prudencial en La Florida del Inca de Garcilaso de la Vega". Herencia cultural de España en América. Siglos XVII y XVIII. Coord. Trinidad Barrera López. Madrid: Iberoamericana, 2008. 231-254.

Kristeller, Paul Oskar. Renaissance thought and the arts. Princeton: Princeton University Press, 1990.

McClure, George. Sorrow and consolation in Italian humanism. Princeton: Princeton University Press, 1991.

Miró Quesada, Aurelio. "Creación y elaboración de La Florida del Inca”. Cuadernos americanos 18 (1989): 152-171. 
Petrarca, Francisco. De los remedios contra próspera y adversa fortuna. Trad. Francisco de Madrid. Zaragoza, 1518.

Vives, Juan Luis. Introducción a la sabiduría. En Obras que Francisco Cervantes de Salazar ha hecho, glosado i traducido. Madrid, 1772.

El arte retórica. De ratione dicendi. Trad. Ana Isabel Camacho. Barcelona: Anthropos Editorial, 1998.

Opera omnia. Tomus I. Valencia: Oficina de Benedicti Monfort, 1782.

Warburg, Aby. "Le ultime volontà di Francesco Sassetti”. La rinascita del paganesimo antico. Trad. Emma Cantimori. Firenze: La Nuova Italia, 1996.

Wittkower, Rudolf. "Chance, time and virtue". Journal of the Warburg Institute 1/ 4 (1938): 313-321. 